\title{
Piperazin İçeren Polimerik Co(II), Ni(II), Zn(II) ve Cd(II) Sakkarin Komplekslerinin Sentezi, Spektroskopik ve Termik Özellikleri
}

\author{
Serkan GÜNEY \\ Ordu Üniversitesi, Ulubey Meslek Yüksekokulu, Kimya ve Kimyasal İşleme Teknolojileri Bölümü, Ordu, Türkiye
}

Geliş Tarihi: 18.09 .2017

Sorumlu Yazar: guneyserkan@ odu.edu.tr

Kabul Tarihi: 26.10.2017

Özet

$\left[\mathrm{M}(\mathrm{sac})_{2}\left(\mathrm{H}_{2} \mathrm{O}\right)_{4}\right] 2 \mathrm{H}_{2} \mathrm{O}(\mathrm{M}=\mathrm{Co}(\mathrm{II}), \mathrm{Ni}(\mathrm{II}), \mathrm{Zn}(\mathrm{II})$ ve $\mathrm{Cd}(\mathrm{II}), s a c=$ sakkarinat anyonu)'nun piperazin(ppz) ile reaksiyonu sonucu yeni kompleksler sentezlendi. Kompleksler elementel analiz, manyetik ölçümler, FT-IR spektroskopisi ve termik analiz çalışmalarıyla karakterize edildi. Tüm komplekslerin IR spektrumu ppz ve sac ligantlarının tipik absorpsiyon bantlarını göstermektedir. Komplekslerin termik analiz çalışmalarında, ilk basamak yapıdan akua ligandının uzaklaşmasına karşılık gelir. Ardından takip eden basamaklarda $p p z$ ligandı uzaklaşır, son olarak da sac uzaklaşarak karşılık gelen metal oksitler ele geçer.

Anahtar Kelimeler: Polimerik Sakkarin Kompleksleri, Piperazin, Co(II), Ni(II), Zn(II), Cd(II).

\section{Synthesis, Spectroscopic and Thermal Characteristics of Polymeric Co(II), $\mathrm{Ni}(\mathrm{II}), \mathrm{Zn}(\mathrm{II})$ and $\mathrm{Cd}(\mathrm{II})$ Saccharin Complexes Containing Piperazine}

\begin{abstract}
The reaction of $\left[\mathrm{M}(\mathrm{sac})_{2}\left(\mathrm{H}_{2} \mathrm{O}\right)_{4}\right] \quad 2 \mathrm{H}_{2} \mathrm{O} \quad(\mathrm{M}=\mathrm{Co}(\mathrm{II}), \mathrm{Ni}(\mathrm{II}), \mathrm{Zn}(\mathrm{II})$ and $\mathrm{Cd}(\mathrm{II})$; sac = saccharinate anion) with piperazine $(p p z)$ results in the formation of the new complexes. The complexes have been characterized by elemental analyses, magnetic measurements, FT-IR spectroscopy and thermal analysis. The IR spectrum of all the complexes displays typical absorption bands of $p p z$ and sac ligands. In the thermal analysis studies of the complexes, the first decomposition stage corresponds to the decomposition of aqua ligand. In the following stages the decomposition of $p p z$ ligand takes place and the sac decomposes at the final stage of the decomposition to give the metal oxides.
\end{abstract}

Keywords: Polymeric Saccharinate Complexes, Piperazine, Co(II), Ni(II), Zn(II), Cd(II). 


\section{Giriş}

Sakkarin(1,2-benzoisothiazol-3(2H)-on-1,1-dioxide veya o-benzosulfimide olarak ta adlandırılır) en bilinen ve en yaygın kullanılan suni tatlandırıcılardan biridir ve ticari olarak suda çözünen alkali tuzları şeklinde temin edilir. Moleküler sakkarinin metal kompleksi bilinmemekle birlikte, sodyum sakkarinat çözeltisinden elde edilen sakkarinat(sac) anyonu, hem negatif yüklü N atomuna ve hem de $\mathrm{CO}$ ve $\mathrm{SO}_{2}$ gruplarına sahiptir ve tüm bu donör kısımları ile metallere koordine olabilmektedir (Baran ve Yılmaz, 2006). Sac bu çok fonksiyonlu ligant özelliği sayesinde çok tercih edilen bir ligant olmuştur. Ayrıca son yıllarda sac komplekslerinin anti-kanser özellik gösterdiğinin belirlenmesi ile sac'a olan ilgi artmıştır (Ulukaya ve ark., 2011; Ari ve ark., 2013; 2014; Al-Jibori ve ark., 2014).

Piperazin(ppz) ligandı sahip olduğu N atomu ile metallere tek dişli (Hou ve ark., 2004) olarak koordine olabilmektedir. Ayrıca iki metal merkezi arasında köprü koordinasyonu da sağlayabilmektedir (Suen ve ark., 2002; Zhao ve ark., 2004). Ppz bu köprü ligandı özelliği sayesinde koordinasyon polimeri oluşturmak için kullanılmaktadır.

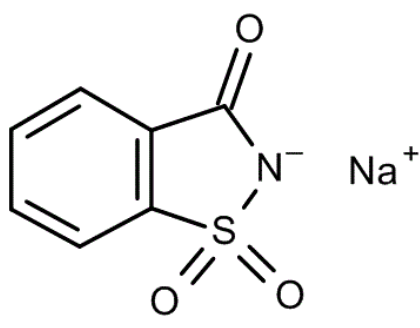

Sodyum sakkarinat

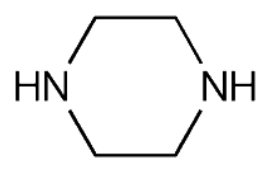

Piperazin

Sac ve ppz ligantlarını içeren $\left[\mathrm{Cu}(\mathrm{sac})_{2}(\mathrm{ppz})\left(\mathrm{H}_{2} \mathrm{O}\right)\right]_{\mathrm{n}}$ kompleksi sentezlenmiş ve yapısı aydınlatılmıştır (Yılmaz ve ark., 2008). $\left[\mathrm{Cu}(\mathrm{sac})_{2}(\mathrm{ppz})\left(\mathrm{H}_{2} \mathrm{O}\right)\right]_{\mathrm{n}}$ polimerik kompleksinde bakır(II) iyonu bir nötral ppz ligand1, iki anyonik sac ligandı ve bir akua ligandı tarafindan koordine edilmiştir. Sac ligandı sık gözlenen bağlanma şeklini göstererek, negatif yüklü azot atomu üzerinden tek dişli olarak koordine olmuştur. $P p z$ ligandı ise azot atomlarını kullanarak bakır(II) iyonları arasında köprü vazifesi görmüştür. Bu çalışmada $s a c$ ve ppz'nin $\left[\mathrm{Cu}(\mathrm{sac})_{2}(\mathrm{ppz})\left(\mathrm{H}_{2} \mathrm{O}\right)\right]_{\mathrm{n}}$ kompleksindeki ligant davranışlarına benzer davranış gösterdiği düşünülen $\left[\mathrm{Co}(\mathrm{sac})_{2}(\mathrm{ppz})\left(\mathrm{H}_{2} \mathrm{O}\right)_{2}\right]_{\mathrm{n}}$, $\left[\mathrm{Ni}(\mathrm{sac})_{2}(\mathrm{ppz})\left(\mathrm{H}_{2} \mathrm{O}\right)_{2}\right]_{\mathrm{n}}, \quad\left[\mathrm{Zn}(\mathrm{sac})_{2}(\mathrm{ppz})\left(\mathrm{H}_{2} \mathrm{O}\right)\right]_{\mathrm{n}} \quad$ ve $\quad\left[\mathrm{Cd}(\mathrm{sac})_{2}(\mathrm{ppz})\left(\mathrm{H}_{2} \mathrm{O}\right)_{2}\right]_{\mathrm{n}} \quad$ kompleksleri sentezlenerek, yapılarını aydınlatmak amaçlanmıştır. 


\section{Materyal ve Metot}

\subsection{Materyal ve Kullanılan Cihazlar}

Komplekslerin sentezinde Merck marka $\mathrm{Na}(\mathrm{sac})_{2} \cdot \mathrm{H}_{2} \mathrm{O}$, ppz, ve metal tuzları olarak $\mathrm{Co}(\mathrm{OAc})_{2} .4 \mathrm{H}_{2} \mathrm{O}, \mathrm{NiCl}_{2} .2 \mathrm{H}_{2} \mathrm{O}, \mathrm{Zn}\left(\mathrm{NO}_{3}\right)_{2} .2 \mathrm{H}_{2} \mathrm{O}$ ve $\mathrm{Cd}(\mathrm{OAc})_{2} .2 \mathrm{H}_{2} \mathrm{O}$; çözücü olarak da yine Merck marka metanol kullanıld1.

Komplekslerin elementel analizleri (C, $\mathrm{H}$ ve $\mathrm{N}$ analizi) Vario EL Elemental Analyser cihazında yapılmıştır. IR spektrumları KBr ile disk yapılarak Mattson 1000 FTIR spektrometrisiyle 4000-400 $\mathrm{cm}^{-1}$ aralı̆̆ında kaydedilmiştir. Komplekslerin UV-VIS spektrumu, Unicam UV2 marka UV/VIS spektrometresinde çözücü olarak metanol ve etanol kullanılarak, 200-900 nm aralığında kaydedildi. Manyetik ölçümler MX I Model Sherwood Scientific manyetik duyarlılık terazisiyle, Evans yöntemine göre yapıldı. Termal analiz eğrileri (TG ve DTA) Rigaku TG8110 termal analiz cihazından statik bir hava atmosferinde 5-10 mg'lık numune kullanılarak elde edilmiştir.

\subsection{Metot}

\subsubsection{Sentez}

Komplekslerin hazırlanmasında başlangıç maddesi olarak literatürdeki metotlarla sentezlenen $\left[\mathrm{M}(\mathrm{sac})_{2}\left(\mathrm{H}_{2} \mathrm{O}\right)_{4}\right] \cdot 2 \mathrm{H}_{2} \mathrm{O}[\mathrm{M}=\mathrm{Co}(\mathrm{II}), \mathrm{Ni}(\mathrm{II}), \mathrm{Zn}(\mathrm{II})$ veya $\mathrm{Cd}(\mathrm{II})]$ kullanıldı (Haider ve ark., 1985). 1 mmol tetraakuabis(sakkarinato)metal(II) dihidrat, $30 \mathrm{ml}$ metanolde çözülerek üzerine $10 \mathrm{ml}$ metanolde $2 \mathrm{mmol}(0,172 \mathrm{~g}) \mathrm{ppz}$ çözülerek hazırlanan çözelti damla damla ilave edildi. Karışım 1 saat manyetik karıştırıcı üzerinde karıştırıldı. Birkaç gün içinde kompleksler toz halde elde edildi.

\section{Bulgular ve Tartışma}

\subsection{Elementel Analiz}

Sentezlenen komplekslerinin renk, verim, bozunma noktası ve önerilen molekül formülüne göre elementel analiz verileri Tablo 1'de verilmiştir. Kompleksler genellikle \% 70' in üzerinde yüksek verimlerle elde edildi. Kompleksler havada kararlı olup, nem çekici özellikleri bulunmamakta ve yaygın çözücülerde ancak ısıtıldıklarında çözünmektedirler. Tüm komplekslerin 
belirli bir erime noktasının olmadığı ve Tablo 1' de verilen sıcaklıklarda bozunduğu tespit edilmiştir.

Tablo 1. Komplekslerin renk, verim, bozunma noktası ve elementel analiz verileri

\begin{tabular}{|c|c|c|c|c|c|c|c|}
\hline \multirow{2}{*}{ Kompleksler } & \multirow{2}{*}{ Renk } & \multirow{2}{*}{$\begin{array}{l}\text { Bozunma } \\
\text { Noktası }\left({ }^{\circ} \mathrm{C}\right)\end{array}$} & \multirow{2}{*}{$\begin{array}{l}\text { Molekül } \\
\text { Ağırlığı }\end{array}$} & \multicolumn{3}{|c|}{$\%$ Bileşim $^{a}$} & \multirow{2}{*}{$\begin{array}{c}\text { Verim } \\
(\%)\end{array}$} \\
\hline & & & & C & $\mathbf{H}$ & $\mathbf{N}$ & \\
\hline $\begin{array}{l}{\left[\mathrm{Co}(\mathrm{sac})_{2}(\mathrm{ppz})\left(\mathrm{H}_{2} \mathrm{O}\right)_{2}\right]_{\mathrm{n}}} \\
\mathrm{C}_{18} \mathrm{H}_{22} \mathrm{~N}_{4} \mathrm{O}_{8} \mathrm{~S}_{2} \mathrm{Co}\end{array}$ & Kırmız1 & 49 & 545,46 & $\begin{array}{c}39,48 \\
(39,64)\end{array}$ & $\begin{array}{c}4,39 \\
(4,06)\end{array}$ & $\begin{array}{c}10,31 \\
(10,27)\end{array}$ & 90 \\
\hline $\begin{array}{l}{\left[\mathrm{Ni}(\mathrm{sac})_{2}(\mathrm{ppz})\left(\mathrm{H}_{2} \mathrm{O}\right)_{2}\right]_{\mathrm{n}}} \\
\mathrm{C}_{18} \mathrm{H}_{22} \mathrm{~N}_{4} \mathrm{O}_{8} \mathrm{~S}_{2} \mathrm{Ni}\end{array}$ & Yeşil & 71 & 545,20 & $\begin{array}{c}39,56 \\
(39,65)\end{array}$ & $\begin{array}{c}4,10 \\
(4,07)\end{array}$ & $\begin{array}{c}10,32 \\
(10,28)\end{array}$ & 90 \\
\hline $\begin{array}{l}{\left[\mathrm{Zn}(\mathrm{sac})_{2}(\mathrm{ppz})\left(\mathrm{H}_{2} \mathrm{O}\right)\right]_{\mathrm{n}}} \\
\mathrm{C}_{18} \mathrm{H}_{20} \mathrm{~N}_{4} \mathrm{O}_{7} \mathrm{~S}_{2} \mathrm{Zn}\end{array}$ & Beyaz & 78 & 533,88 & $\begin{array}{c}40,12 \\
(40,49)\end{array}$ & $\begin{array}{c}3,95 \\
(3,78)\end{array}$ & $\begin{array}{c}10,44 \\
(10,49)\end{array}$ & 92 \\
\hline $\begin{array}{l}{\left[\mathrm{Cd}(\mathrm{sac})_{2}(\mathrm{ppz})\left(\mathrm{H}_{2} \mathrm{O}\right)_{2}\right]_{\mathrm{n}}} \\
\mathrm{C}_{18} \mathrm{H}_{22} \mathrm{~N}_{4} \mathrm{O}_{8} \mathrm{~S}_{2} \mathrm{Cd}\end{array}$ & Beyaz & 93 & 598,93 & $\begin{array}{r}35,95 \\
(36,01) \\
\end{array}$ & $\begin{array}{c}3,24 \\
(3,70) \\
\end{array}$ & $\begin{array}{c}9,18 \\
(9,35) \\
\end{array}$ & 88 \\
\hline
\end{tabular}

Komplekslerde metal:sac:ppz oranının $\left[\mathrm{Cu}(\mathrm{sac})_{2}(\mathrm{ppz})\left(\mathrm{H}_{2} \mathrm{O}\right)\right]_{\mathrm{n}}$ kompleksindeki gibi 1:2:1 olduğu önerilmektedir. Komplekslerin önerilen yapılarında hesaplanan ve bulunan elementel analiz değerleri oldukça yüksek bir uyum içindedir. Komplekslerin önerilen molekül yapıları Şekil 1 ve Şekil 2’ de verilmiştir.

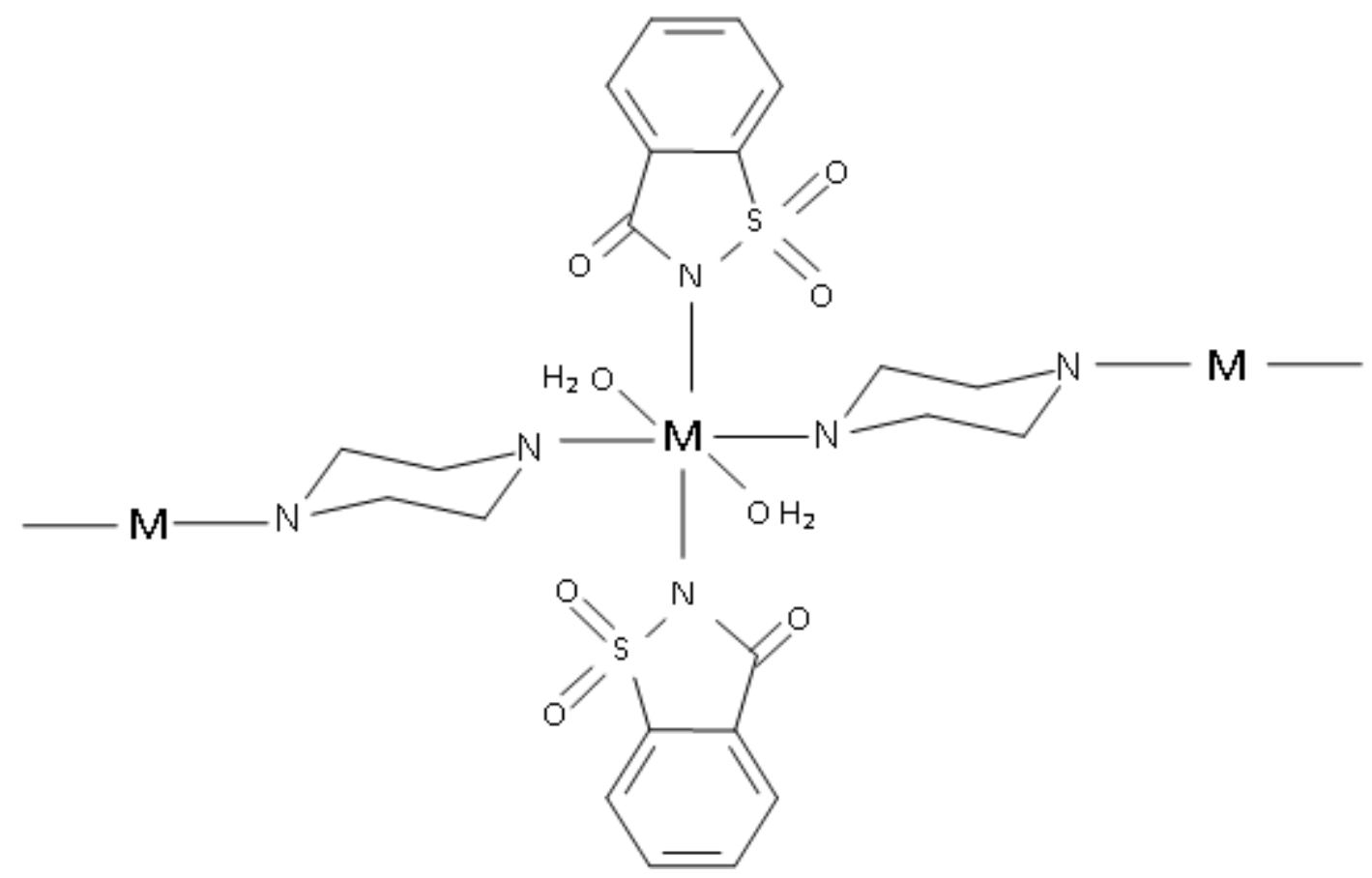

Şekil 1. $\left[\mathrm{M}(\mathrm{sac})_{2}(\mathrm{ppz})\left(\mathrm{H}_{2} \mathrm{O}\right)_{2}\right]_{\mathrm{n}}(\mathrm{M}=\mathrm{Co}(\mathrm{II}), \mathrm{Ni}(\mathrm{II}), \mathrm{Cd}(\mathrm{II}))$ komplekslerinin önerilen molekül yapısı 


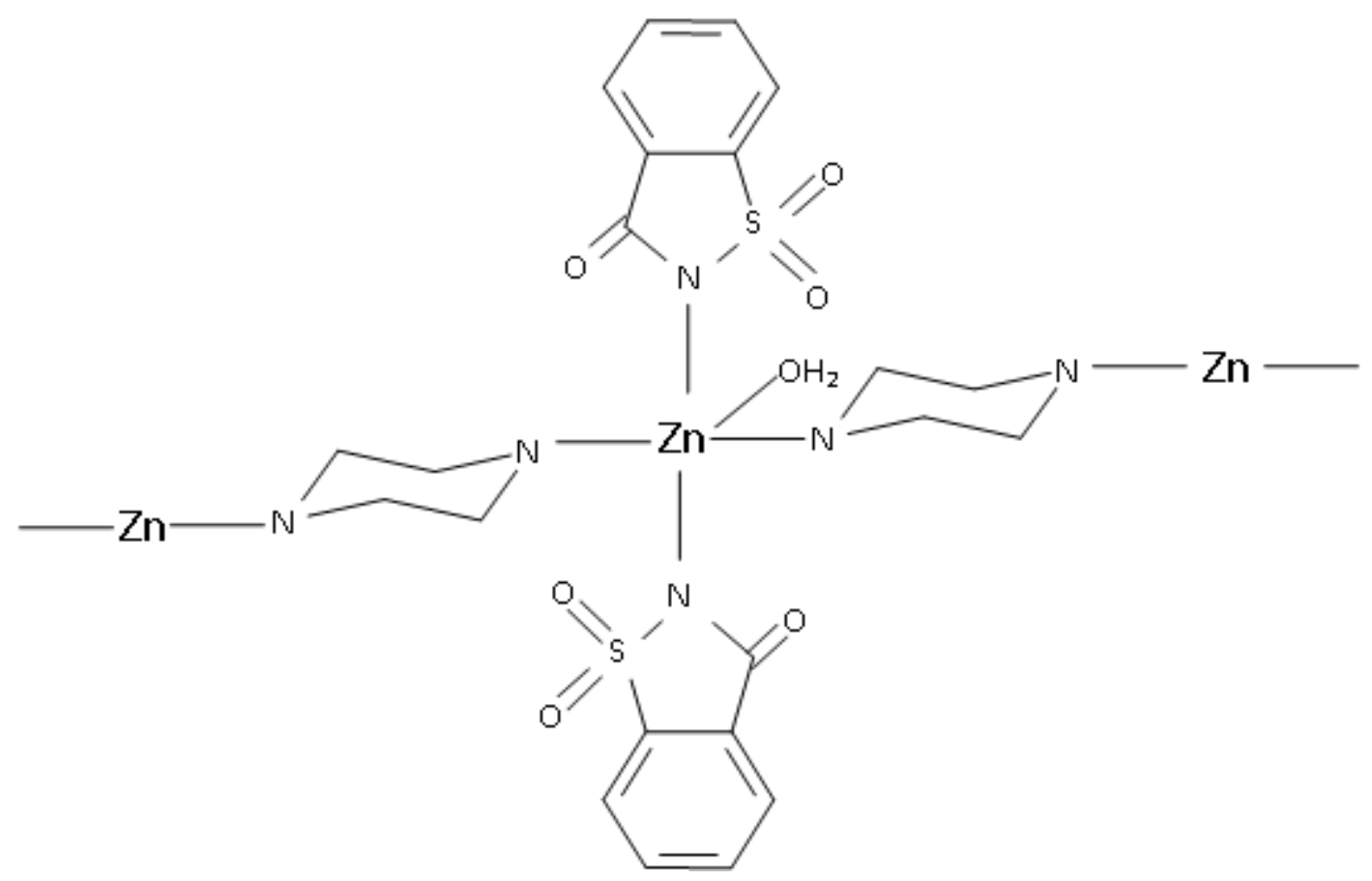

Şekil 2. $\left[\mathrm{Zn}(\mathrm{sac})_{2}(\mathrm{ppz})\left(\mathrm{H}_{2} \mathrm{O}\right)\right]_{\mathrm{n}}$ kompleksinin önerilen molekül yapıs1

\subsection{UV-VIS Çalışmaları ve Manyetik Moment Ölçümleri}

Komplekslerin UV-VIS spektrumları metanol içinde $1 \times 10^{-3} \mathrm{M}$ çözeltileri hazırlanarak kaydedildi. UV-VIS ve manyetik moment ölçüm çalışmalarına ilişkin veriler Tablo 2' de özetlenmiştir.

Tablo 2. Komplekslerin UV-VIS ve manyetik moment verileri

\begin{tabular}{lccc}
\hline \multirow{2}{*}{ Kompleksler } & \multicolumn{2}{c}{$\boldsymbol{\lambda}_{\max }(\mathbf{n m}) ; \boldsymbol{\varepsilon}\left(\mathbf{M}^{-\mathbf{1}} \mathbf{c m}^{-\mathbf{1}}\right)^{\mathbf{a}}$} & $\boldsymbol{\mu}_{\text {s }}$ bul.(hesap.) \\
\cline { 2 - 4 } & Ligant & $\boldsymbol{d}$ - $\boldsymbol{d}$ & $(\mathbf{M})$. \\
\hline$\left[\mathrm{Co}(\mathrm{sac})_{2}(\mathrm{ppz})\left(\mathrm{H}_{2} \mathrm{O}\right)_{2}\right]_{\mathrm{n}}$ & $238(1454)$ & $422(4), 511(19)$ & $3,83(3,87)$ \\
{$\left[\mathrm{Ni}(\mathrm{sac})_{2}(\mathrm{ppz})\left(\mathrm{H}_{2} \mathrm{O}\right)_{2}\right]_{\mathrm{n}}$} & $237(827), 283(589), 302(593)$ & $395(19), 658(10)$ & $2,84(2,83)$ \\
{$\left[\mathrm{Zn}(\mathrm{sac})_{2}(\mathrm{ppz})\left(\mathrm{H}_{2} \mathrm{O}\right)\right]_{\mathrm{n}}$} & $236(2003), 299(1390)$ & - & Diyamanyetik \\
{$\left[\mathrm{Cd}(\mathrm{sac})_{2}(\mathrm{ppz})\left(\mathrm{H}_{2} \mathrm{O}\right)_{2}\right]_{\mathrm{n}}$} & $236(1723), 260(1322)$ & - & Diyamanyetik \\
\hline${ }^{\mathrm{a}} \boldsymbol{\varepsilon}$ değerleri parantez içinde verilmiştir. & &
\end{tabular}

${ }^{\mathrm{a}} \varepsilon$ değerleri parantez içinde verilmiştir.

Komplekslerin UV-VIS spektrumları genel olarak değerlendirildiğinde, 236-302 nm aralığında sac ve $p p z$ ligantlarının yüksek şiddetli $\pi \rightarrow \pi^{*}$ ve $\mathrm{n} \rightarrow \pi^{*}$ geçişlerine ait pikler görünmektedir. Co(II) ve Ni(II) komplekslerinin düşük şiddetli $d$ - $d$ geçişlerine ait pikler 395-658 $\mathrm{nm}$ aralığında görünmektedir. $\mathrm{d}^{10}$ yapılı $\mathrm{Zn}$ (II) ve $\mathrm{Cd}$ (II) komplekslerinde beklenildiği gibi görünür bölgede hiç pik gözlenmemiştir. 
Co(II) ve Ni(II) komplekslerinin oktahedral geometriye göre hesaplanan manyetik moment değerleri ile deneysel değerler uyumludur.

\section{3. İnfrared (IR) Çalışmaları}

Komplekslerinin IR spektrumları $\mathrm{KBr}$ ile disk yapılarak kaydedildi. Komplekslerin IR spektrumlarından elde edilen önemli gerilme titreşimlerine ait frekans $\left(\mathrm{cm}^{-1}\right)$ değerleri Tablo $3^{\prime}$ te verilmiştir.

Tablo 3. Komplekslerin IR spektrum verileri

\begin{tabular}{|c|c|c|c|c|c|c|c|c|}
\hline Kompleksler & $v(\mathbf{O H})$ & $v(\mathrm{NH})$ & $v(\mathbf{C H})$ & $v(C=O)$ & $V_{\text {asym }}\left(\mathbf{S O}_{2}\right)$ & $v_{\text {sym }}\left(\mathbf{S O}_{2}\right)$ & $v_{\text {sym }}(\mathrm{CNS})$ & Vasym(CNS) \\
\hline$\left[\mathrm{Co}(\mathrm{sac})_{2}(\mathrm{ppz})\left(\mathrm{H}_{2} \mathrm{O}\right)_{2}\right]_{\mathrm{n}}$ & 3521 ş,k & 3245 ş,k & $\begin{array}{l}2968 z- \\
2817 z\end{array}$ & $1622 s ̧, \mathrm{k}$ & $1279 \mathrm{~s}, \mathrm{k}$ & 1153 ş,k & $1344 o$ & 957 ş,k \\
\hline$\left[\mathrm{Ni}(\mathrm{sac})_{2}(\mathrm{ppz})\left(\mathrm{H}_{2} \mathrm{O}\right)_{2}\right]_{\mathrm{n}}$ & 3531ş,k & $3246 s ̧, k$ & $\begin{array}{l}2978 z- \\
2870 z\end{array}$ & 1630 ş,k & $1279 \mathrm{~s}, \mathrm{k}$ & 1157 ş,k & $1344 \mathrm{o}$ & 960 ş,k \\
\hline$\left[\mathrm{Zn}(\mathrm{sac})_{2}(\mathrm{ppz})\left(\mathrm{H}_{2} \mathrm{O}\right)\right]_{\mathrm{n}}$ & $3379 \mathrm{~s}, \mathrm{k}$ & 3197 ş,k & $\begin{array}{l}2937 \mathrm{z}- \\
2824 \mathrm{z}\end{array}$ & $\begin{array}{l}1651 s ̧, \mathrm{k}, \\
1624 s, \mathrm{k}\end{array}$ & 1273 ş,k & 1151 ş,k & 1334 ş,k & 962 ş,k \\
\hline$\left[\mathrm{Cd}(\mathrm{sac})_{2}(\mathrm{ppz})\left(\mathrm{H}_{2} \mathrm{O}\right)_{2}\right]_{\mathrm{n}}$ & 3355 ş,k & 3211 ş,k & $\begin{array}{l}2962 z- \\
2835 z\end{array}$ & $\begin{array}{l}1647 \text { s, }, \\
1620, \mathrm{~s}, \mathrm{k}\end{array}$ & 1269 ş, $\mathrm{k}$ & 1153 ş,k & 1334 ş,k & 968 ş,k \\
\hline
\end{tabular}

ş: şiddetli, k: keskin, o: orta, z: zayıf

Tüm komplekslerin IR spektrumu birbirine benzemekte ve benzer bir yapısal ilişki göstermektedir. Komplekslerde akua ligandının O-H gerilme titreşimi $3355-3531 \mathrm{~cm}^{-1}$ aralığında gözlenmiştir. Ppz' nin karakteristik N-H gerilme titreşimleri 3197-3246 cm cm $^{-1}$ aralığında gözlenmiştir. 2824-2978 $\mathrm{cm}^{-1}$ aralığındaki bantlar komplekslerin C-H titreşimlerinden

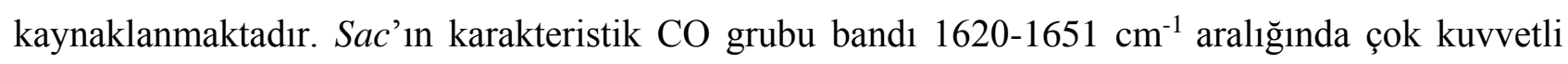
olarak meydana gelir. Asimetrik ve simetrik $\mathrm{SO}_{2}$ gerilme titreşimleri sirasıyla $1269-1279 \mathrm{~cm}^{-1}$ aralığında ve $1151-1157 \mathrm{~cm}^{-1}$ aralığında meydana gelir. $1334-1344 \mathrm{~cm}^{-1}$ aralığındaki ve 957-968 $\mathrm{cm}^{-1}$ aralığındaki bantlar sac' ların asimetrik ve simetrik CNS gerilme titreşimleridir.

\subsection{Termik Analiz Çalışmaları}

Sentezlenen komplekslerinin eş zamanlı TG ve DTA eğrileri kaydedildi. Komplekslerin termik analiz eğrilerinden elde edilen termoanalitik sonuçlar Tablo 4' te verilmiştir.

Komplekslerin TG ve DTA eğrileri incelendiğinde, akua ligandının ayrılmasından sonra $p p z$ ligantlarının ayrılışının farklı basamaklarda gerçekleştiği görülmüştür. Geriye kalan metal sakkarinatların bozunarak, metal oksitleri verdikleri düşünülmektedir. Tüm deneysel ağırlık kaybı değerleri hesaplanan değerlerle uyumludur. 
Tablo 4. Komplekslerin TG ve DTA eğrilerinden elde edilen termoanalitik veriler

\begin{tabular}{|c|c|c|c|c|c|c|c|c|}
\hline \multirow[t]{2}{*}{ Kompleksler } & \multirow{2}{*}{$\begin{array}{l}\text { Boz. } \\
\text { Bas. }\end{array}$} & \multirow{2}{*}{$\begin{array}{l}\text { Sicaklık } \\
\text { aralığı } \\
\left({ }^{\circ} \mathrm{C}\right)\end{array}$} & \multirow[t]{2}{*}{ DTA $_{\max }\left({ }^{\circ} \mathrm{C}\right)^{\mathrm{a}}$} & \multicolumn{2}{|c|}{$\begin{array}{l}\begin{array}{l}\text { Kütle } \\
(\%)\end{array} \\
\end{array}$} & \multicolumn{2}{|c|}{$\begin{array}{l}\text { Top.Kütle } \\
\text { Kaybı(\%) }\end{array}$} & \multirow[t]{2}{*}{ Kalan Ürün } \\
\hline & & & & Bul. & Hesap. & Bul. & Hesap. & \\
\hline \multirow[t]{3}{*}[\mathrm{Co}(\mathrm{sac})_{2}(\mathrm{ppz})(\mathrm{H}_{2}\mathrm{O})_{2}]{$_{\mathrm{n}}$} & 1 & $49-122$ & $69(+)$ & 6,2 & 6,6 & & & {$\left[\mathrm{Co}(\mathrm{sac})_{2}(\mathrm{ppz})\right]$} \\
\hline & 2 & $122-294$ & $185(+), 285(-)$ & 16,3 & 15,8 & & & {$\left[\mathrm{Co}(\mathrm{sac})_{2}\right]$} \\
\hline & 3 & $294-816$ & $374(-), 467(-), 533(-)$ & 66,5 & 66,8 & 89,0 & 89,2 & $\mathrm{CoO}$ \\
\hline \multirow[t]{3}{*}[\mathrm{Ni}(\mathrm{sac})_{2}(\mathrm{ppz})(\mathrm{H}_{2}\mathrm{O})_{2}]{$_{\mathrm{n}}$} & 1 & $71-121$ & $107(+)$ & 6,6 & 6,6 & & & {$\left[\mathrm{Ni}(\mathrm{sac})_{2}(\mathrm{ppz})\right]$} \\
\hline & 2 & $121-367$ & $256(-)$ & 16,0 & 15,8 & & & {$\left[\mathrm{Ni}(\mathrm{sac})_{2}\right]$} \\
\hline & 3 & $367-794$ & $405(-), 493(-)$ & 66,1 & 66,8 & 88,7 & 89,2 & $\mathrm{NiO}$ \\
\hline \multirow{3}{*}[\mathrm{Zn}(\mathrm{sac})_{2}(\mathrm{ppz})(\mathrm{H}_{2}\mathrm{O})]{$_{\mathrm{n}}$} & 1 & $49-154$ & $78(+)$ & 3,7 & 3,4 & & & {$\left[\mathrm{Zn}(\mathrm{sac})_{2}(\mathrm{ppz})\right]$} \\
\hline & 2 & $154-384$ & $209(+), 275(+)$ & 15,6 & 16,1 & & & {$\left[\mathrm{Zn}(\mathrm{sac})_{2}\right]$} \\
\hline & 3 & $384-569$ & $441(+), 519(-)$ & 69,1 & 68,4 & 88,4 & 87,9 & $\mathrm{ZnO}$ \\
\hline \multirow[t]{3}{*}[\mathrm{Cd}(\mathrm{sac})_{2}(\mathrm{ppz})(\mathrm{H}_{2}\mathrm{O})_{2}]{$_{\mathrm{n}}$} & 1 & $93-159$ & $145(+)$ & 6,1 & 6,0 & & & $\mathrm{Cd}(\mathrm{sac})_{2}(\mathrm{ppz})$ \\
\hline & 2 & $302-346$ & $339(-)$ & 11,7 & 14,4 & & & $\mathrm{Cd}(\mathrm{sac})_{2}$ \\
\hline & 3 & $346-982$ & $451(-), 590(-)$ & 62,7 & 60,8 & 80,5 & 81,2 & $\mathrm{CdO}$ \\
\hline
\end{tabular}

${ }^{\mathrm{a}}(+)$ :Endotermik, (-):Ekzotermik

\section{Sonuçlar ve Öneriler}

Çalışmada $p p z$, içeren 4 adet yeni karışık ligantlı metal-sac kompleksleri sentezlenerek, bu komplekslerin yapıları elementel analiz, manyetik duyarlılık ölçümleri, UV-VIS ve IR spektroskopisi teknikleri ve termik analiz çalışmalarıyla belirlendi. Komplekslerin polimerik yapıda olduğu, $\mathrm{Co}(\mathrm{II}), \mathrm{Ni}(\mathrm{II})$ ve $\mathrm{Cd}$ komplekslerinin formülünün $\left[\mathrm{M}(\mathrm{sac})_{2}(\mathrm{ppz})\left(\mathrm{H}_{2} \mathrm{O}\right)_{2}\right]_{\mathrm{n}}, \mathrm{Zn}(\mathrm{II})^{\prime}$ nin molekül formülünün ise $\left[\mathrm{Zn}(\mathrm{sac})_{2}(\mathrm{ppz})\left(\mathrm{H}_{2} \mathrm{O}\right)\right]_{\mathrm{n}}$ olduğu önerildi. Komplekslerin tümü yüksek verimde elde edilmiştir ve havaya karşı kararlıdırlar. Kullanılan çözücüler ve ortam koşulları değiştirilerek, tek kristali elde edilemeyen bu komplekslerin tek kristalleri elde edilerek yapıları tamamen aydınlatılabilir. Elde edilen komplekslerin biyolojik aktiviteleri ve elektrokimyasal davranışları araştırılabilir.

\section{Kaynaklar}

Baran, E. J. ve Y1lmaz, V. T. (2006). Metal complexes of saccharin. Coordination Chemistry Reviews, 250, 1981-1999.

Ulukaya, E., Ari, F., Dimas, K., İkitimur, E. İ., Güney, E. ve Yılmaz, V. T. (2011). Anti-cancer activity of a novel palladium(II) complex on human breast cancer cells in vitro and in vivo. European Journal of Medicinal Chemistry, 46, 4957-4963.

Ari, F., Ulukaya, E., Sarımahmut, M. ve Yılmaz, V. T. (2013). Palladium(II) saccharinate complexes with bis(2-pyridylmethyl) amine induce cell death by apoptosis in human breast cancer cells in vitro. Bioorganic\&Medicinal Chemistry, 21, 3016-3021.

Ari, F., Aztopal, N., İçsel, C., Yılmaz, V. T., Güney, E., Büyükgüngör, O. ve Ulukaya, E. (2013). Synthesis, structural characterization and cell death-inducing effect of novel palladium(II) and platinum(II) saccharinate complexes with 2-(hydroxymethyl)pyridine and 2-(2-hydroxyethyl)pyridine on cancerve cells in vitro. Bioorganic\&Medicinal Chemistry, 21, 6427-6434.

Al-Jibori, S. A., Al-Jibori, G. H., Al-Hayaly, L. J., Wagner, C., Schmidt, H., Timur, S., Barlas, F. B., Subaş1, E., Ghosh, S. ve Hogarth, G. (2014). Combining anti-cancer drugs with artificial sweeteners: Synthesis 
and anti-cancer activity of saccharinate (sac) and thiosaccharinate (tsac) complexes cis$\left[\mathrm{Pt}(\mathrm{sac})_{2}\left(\mathrm{NH}_{3}\right)_{2}\right]$ and cis-[Pt(tsac $\left.)_{2}\left(\mathrm{NH}_{3}\right)_{2}\right]$. Journal of Inorganic Biochemistry, 141, 55-57.

Ari, F., Cevatemre, B., İkitimur Armutak, E. İ., Aztopal, N., Yilmaz, V. T. ve Ulukaya, E. (2014). Apoptosis-inducing effect of a palladium(II) saccharinate complex of terpyridine on human breast cancer cells in vitro and in vivo. Bioorganic\&Medicinal Chemistry, 22, 4948-4954.

Suen, M. C., Keng, T. C. ve Wang, J. C. (2002). One-dimensional structures of zinc(II) and cobalt(II) coordination complexes $\left[\mathrm{Zn}(\mathrm{NCS})_{2}(\mathrm{PPz})\right]_{\mathrm{n}}$ and $\left[\mathrm{CoCl}_{2}(\mathrm{PPz})\right]_{\mathrm{n}}(\mathrm{PPz}=$ piperazine). Polyhedron, 21, 2705-2710.

Zhao, X. J., Du, M., Wang, Y. ve Bu, X. H. (2004). Formation of cobalt(II)-piperazine supramolecular systems under different organic acid mediums: synthesis, characterization and crystal structures. Journal of Molecular Structure, 692, 155-161.

Y1lmaz, V. T., Güney, S. ve Kazak, C. (2008). Copper(II)-saccharinato complexes with piperazine and N-(2aminoethyl)piperazine ligands. Polyhedron, 27, 1381-1386.

Haider, S. Z., Malik, K. M. A. ve Ahmed, K. J. (1985). Metal Complexes of Saccharin, Inorganic Syntheses, $23,47-51$. 